\title{
Residential relocations and academic performance of Australian children: A longitudinal analysis
}

\author{
Sergi Vidal \\ svidal@ced.uab.es \\ Janeen Baxter
}

\begin{abstract}
Centre for Demographic Studies, CERCA - Centres de Recerca de Catalunya, Spain; and Australian Research Council Centre of Excellence for Children and Families Over the Life Course, Australia
\end{abstract}

Australian Research Council Centre of Excellence for Children and Families Over the Life Course, Australia

(Received November 2016

Revised October 2017)

http://dx.doi.org/10.14301/Ilcs.v9i2.435

\section{Abstract}

The family and residential environments are critical to children's wellbeing and, hence, residential change can affect children's developmental outcomes. In this research, we study the associations between residential relocations and academic performance in the Australian context using panel regression methods on longitudinal data of a representative sample of 3,481 children born in the late 1990s from the Longitudinal Study of Australian Children (LSAC). We examine the impact of residential relocations from infancy to middle childhood and pay special attention to the distance, frequency and developmental age-stage of relocations on academic test scores from the National Assessment Program - Literacy and Numeracy (NAPLAN) of third, fifth and seventh graders. Consistent with previous research, we find that the associations between childhood relocations and school performance are generally small. Frequent relocations during childhood relate to poor academic performance, but the association vanishes after controlling for family and home circumstances. In contrast, moderate levels of residential mobility, particularly relocations towards a different local area, are associated with improvements in academic performance. Relocations around the time of school entry are associated with poorer academic performance in grade 3 , but are not associated with performance in grades 5 and 7 . Our findings suggest that while moving home is not per se a major determinant of academic performance, the contexts and environments where children are embedded matter. We conclude that further research is needed on what and how intersections between relocation biographies and contexts matter for children's development.

\section{Keywords}

Residential relocations; academic performance; longitudinal data; LSAC; Australia

\section{Introduction}

In recent years, there has been an increasing interest in understanding developmental outcomes of children's residential relocations. An underlying concern is that the home and residential environments are critical for children's functioning and hence, residential relocations may affect their development and have impacts on outcomes later in life (Ackerman, Kogos, Youngstrom, Schoff, \& Izard 1999; Adam \& Chase-Lansdale, 2002; Rumbold et al., 2012; Anderson, Leventhal, Newman \& Dupéré, 2014; Lennon, Clark \& Joshi, 2016). Regarding cognitive functioning, research results concurred in finding moderate and weak associations, with children who moved homes 
displaying worse outcomes before and during school, and lower educational attainment (Pribesh \& Downey, 1999; Pettit \& McLanahan, 2003; Rumberger \& Lim, 2008; Evans \& Wachs, 2010). Despite consistency in findings across studies, empirical evidence is ambiguous about how and when relocations have larger impacts on children's cognitive functioning. It remains unclear whether these associations are due to direct impacts of relocations, or due to pre-existing poor cognitive development among children who relocate. Moreover, we know little about whether the potential impacts of age-specific relocations are short-lived or persist in further developmental stages.

We argue here that home relocations, which are standard experiences in childhood, are complex processes with important intersections between individual biographies (i.e. how often, how far, during what developmental stages, and why children moved) and the family and social contexts in which children are embedded. Recently, there have been efforts to investigate more thoroughly the processes that influence the potential adverse (and also beneficial) impacts of relocations on cognitive development (Gasper, Deluca \& Estacion, 2010; Voight, Shinn \& Nation, 2012; Anderson et al., 2014; Gambaro \& Joshi, 2016; Schmitt \& Lipscomb, 2016). Largely focused on the US context, studies have capitalised on recent collections of longitudinal data rich in information on the contexts and circumstances of childhood relocations and the use of adequate methods to make better causal assessments of the associations.

In this article, we investigate the implications of residential relocations from infancy to middle childhood for school performance in the Australian context using longitudinal data and methods. Despite similarities with the US in some economic and cultural aspects, Australia's institutional setting provides greater equality of opportunity through education. For example, access to high-quality early education and care in Australia is less dependent on family income than in the US (Coley, Leventhal, Lynch \& Kull, 2013). As far as we know, no longitudinal analysis has been published for the Australian case, despite two in three Australian children having moved by age 10 (Maguire, Edwards \& Soloff, 2012).

The study brings new insights on the ways in which relocations are related to children's school performance by investigating relevant aspects of relocations (i.e. distance, frequency and age-stage at relocation), and those of the family, residential and school environments. We examine representative data for Australian children born in the late 1990s on lifetime residential relocations and academic test scores of third, fifth and seventh graders from Growing Up in Australia: The Longitudinal Study of Australian Children (LSAC). We deploy methods for panel data analysis, which acknowledge the nested structure of the data, to examine the impacts of relocation lifetime frequency and relocation distance on children's performance and to assess the importance of the developmental age-stage of relocations in shaping school performance trajectories.

\section{Residential relocations and children's educational outcomes}

Residential mobility is a common experience during childhood. The family and residential environments are key factors shaping children's cognitive development (Bronfenbrenner \& Morris, 2006), and, hence, moving the home can affect children's outcomes. Previous studies revealed moderate negative associations, with home relocations entailing poor school performance (Haveman, Wolfe \& Spaulding, 1991; Ingersoll, Scamman \& Eckerling, 1989; Pribesh \& Downey, 1999; Wood, Halfon, Scarlata, Newacheck \& Nessim, 1993), repeating a school grade (Wood et al., 1993), school drop-out (Crowder \& South, 2003; Crowder \& Teachman, 2004; Rumberger \& Lim, 2008) and lower educational attainment (Astone \& McLanahan, 1994; Haveman et al., 1991).

Common mechanisms proposed to explain these associations emphasised the downsides of relocations, such as changes in social relationships and support networks, lack of engagement with the school, as well as changes in household routines of parents and children that produce stress and directly impact school performance (Astone \& McLanahan, 1994; Evans \& Wachs, 2010; South \& Haynie, 2004). Concurrently, other research evidence revealed that children in relocation-prone families were already performing poorly in school before the relocation (Pribesh \& Downey, 1999). These were often children from low-income families who moved house frequently or who reported unfavourable relocation motivations (e.g. eviction, divorce). Thus, the direct effects of residential 
relocations on academic performance might be rather weak or non-existent once accounting for family structures, particularly those that concentrate multiple sources of disadvantage such as lone parents often do (Adam \& Chase-Lansdale, 2002; Anderson et al., 2014; Ersing, Sutphen \& Loeffler, 2009; Gambaro \& Joshi, 2016; Herbers et al., 2012; Pettit \& McLanahan, 2003; Scanlon \& Devine, 2001).

Although the importance of previous research for understanding and potentially supporting children's life chances is indisputable, we believe that whether and how relocations affect cognitive development remain unclear. One major drawback is that the bulk of the existing evidence derives from studies that deployed cross-sectional designs. These studies relied on the examination of one single observation of cognitive ability at a given age stage, and treated residential mobility as a cumulative measure of all prior life relocations. In our view, such research designs cast little light on whether relocations induce or reproduce school performance because the studied associations conflate the immediate impacts of contemporary relocations, the cumulative impacts of past relocations, and pre-existing differences in school performance. The lack of repeated observations of children also hampers ability to compare and contrast the stages when relocations have more relevant impacts on academic performance, or whether these impacts accumulate over time. Developmental psychologists posit that exposure age is not trivial in relation to an impacting event, particularly at stages of noteworthy developmental expansion such as early childhood (Bradley \& Corwyn, 2002). Additionally, life course theory posits that the effects of events earlier in life accumulate and shape later development (Moen, Elder \& Lüscher 1995).

Leveraging growing sources of longitudinal data, recent research investigated the impacts of relocations occurring at different developmental stages on academic performance, and whether these impacts persist over time (Anderson et al., 2014). Analyses deployed a range of multivariate models to assess children's cognitive evolution and showed that developmental stage matters, though there is no agreement on when relocation impacts are stronger. Typically, families with pre-school children move more often than families with school children, because moves during school age are believed to have negative impacts on schooling (Mehana \& Reynolds, 2004). Along these lines, Lawrence, Root \& Mollborn (2015) also found that infants and pre-school age children often move to better neighbourhoods than children who move at later stages. Schmitt and Lipscomb (2016) examined cognitive abilities of low-income pre-school children and found that residential mobility by age four had only modest negative impacts on cognitive abilities by the end of pre-kindergarten. No cumulative effects were observed since the negative impacts of early relocations levelled off by kindergarten and first grade. Voight et al. (2012) found negative effects of early childhood relocation on reading and math skills in third grade, which persisted for reading in later grades. In contrast, Coley \& Kull (2016) found that pre-kindergarten mobility had no effect on cognitive skills during fifth and eighth grade, but school-age mobility had negative effects, though these were moderate and short-lived.

We note that inconsistencies in findings across studies can be due to the uneven interests in the aspects of relocations that were examined. For example, the focus of much research has been limited to the negative impact of highly frequent mobility on cognitive development, often using samples of low-income families. Using a nationally representative sample for the US context, Coley \& Kull (2016) found only a modest negative linear relationship between relocation frequency since birth and children's cognitive ability in fifth grade. A few recent studies have revealed that, under certain conditions, moving had no negative consequences for children's cognitive development (Joshi et al., 2015). Similarly, Ziol-Guest and McKenna (2014) found that children from middleincome families were not susceptible to negative cognitive development if they moved house.

In addition, other aspects of relocations such as the distance moved have received little attention, despite the potential disrupting impacts of longdistance relocations with regards to relevant contexts such as friends, support networks and changing school. Among non-intact families, children's long-distance relocations can potentially reduce the amount of physical contact with the parent who stays behind. However, research is inconclusive on the associations between cognitive development and contact with non-resident parents (Rasmussen \& Stratton, 2012). Moreover, long-distance moves are often motivated by 
positive triggers such as parents' career progress (Huinink, Vidal \& Kley, 2014). Such moves are often accompanied by improvements in household living standards and neighbourhood quality (Clark \& Maas, 2016), which could benefit children, cancelling out the negative consequences of relocating to a new context.

Finally, prior studies often neglected that substandard performance among children who relocate can be due to selective factors or traits. If omitted factors are relevant to cognitive development, the estimated associations are likely to be biased, leading to inaccurate causal interpretations. For instance, certain personality traits of parents leading to instability that are difficult to measure might limit parental provision of cognitive stimulation to children. Such personality traits might enhance household relocation propensities as well. While it is methodologically complex to account for selectivity in cross-sectional analyses, panel regression methods for longitudinal data reduces these potential biases. Based on the exploitation of within-individual variation from repeated observations, some research has improved the causal assessments of the associations under investigation using longitudinal data. Coley et al. (2013) used hierarchical models with a three-level structure and assessed between- and withinindividual effects of housing features and house relocations on children's functioning measures. Coley \& Kull (2016) and Gasper et al. (2010) examined similar associations using, respectively, fixed-effects regression models and a hybrid regression model, which combines virtues of random- and fixed-effects models. These studies modelled within-individual estimators to predict children's development over time, assessing the impacts of changes in covariates and controlling for time-constant unobserved heterogeneity.

The current research makes an original contribution by investigating the associations between residential relocations and children's academic performance in the Australian context. Compared to the US, Australia provides more financial support to families (including self-care of infants and access to high-quality early education). Australian children are also less likely to suffer poverty. The 2011-12 Australian Bureau of Statistics (ABS) Survey of Income and Housing (SIH) showed that $17.7 \%$ of children (under 15 ) were living under the poverty line, defined as $50 \%$ of median income, in 2012 (Australian Council of Social Service, 2014). Using the same income threshold, only $13 \%$ of children (under 18) were under the poverty line according to OECD calculations (OECD, 2017). Lower poverty levels and better early support for children in Australia may have a protective effect from possible detrimental changes in proximal contexts among children. Lower poverty levels may be associated with a lower risk of relocations due to adversity (e.g. eviction, parents' separations) and thus children moving in Australia may be less likely to suffer distress and to potentially benefit from upgrades in home or residential contexts. Additionally, the Australian education system is better equipped to address early identification of learning difficulties that may support children's resilience after relocations, even among those suffering adverse situations. Since previous studies in the US using longitudinal data have found a few negative effects, we expect associations in Australia to be smaller or non-substantive.

We set several research objectives. First, we examine patterns in the associations between agespecific relocations (since infancy until middle school) and school performance. We look into two types of age-related associations: contemporaneous association - which responds to the question: does the association between school performance and relocations vary by age stage? and cumulative association - which responds to the question: are age-specific relocations associated with school performance at later age-stages? Second, we analyse two other relevant aspects of relocations, frequency and distance. Third, we assess whether relocations induce changes in academic performance or reproduce pre-existing performance levels. To this end we exploit the longitudinal aspect of the data to assess betweensubject effects - i.e. differences in school performance between children who relocate and those who do not relocate - and within-subject effects - i.e. differences in individual school performance over time (e.g. before and after relocation). Finally, we identify factors that influence average differences and alterations in school performance of children who relocate.

\section{Method}

To gather adequate evidence of children's residential trajectories and academic performance 
over time, we rely on data from the study Growing Up in Australia: The Longitudinal Study of Australian Children (LSAC). The LSAC is an on-going longitudinal study with a biannual panel design that started in 2004 and is administered by the Australian Federal Department of Social Services (Gray \& Sanson, 2005). The study collects data on parenting, family relationships, childhood education, non-parental childcare, and health of children born in the late 1990s and early 2000s. In 2004, 10,090 families were interviewed, being representative of Australian children aged 0-1 (cohort ' $\mathrm{B}$ ') and 4-5 (cohort ' $\mathrm{K}$ ') living in nonremote areas.

We use longitudinal information from the LSAC cohort ' $K$ ' study (LSAC-K) between 2004 and 2010 (waves 1 to 4), which enables the study of academic performance through the pre-adolescence stage, up to seventh grade. We disregard respondents from cohort ' $B$ ' from our analyses since academic tests scores were only available in one wave at the time the analyses were done.

To assess complete histories of residence and academic performance in middle childhood, we restrict the analytical sample to respondents who participated in the first four survey waves. The original sample size (wave 1 ) of LSAC-K was $n=4,983$ children, and by 2010 (wave 4) the sample of respondents who provided a response was $n=$ 4,163. Sample attrition after four waves of the study involved less than $20 \%$ of original respondents; hence attrition rates in LSAC-K are not higher than those of comparable national household panel studies. Regarding sources of attrition, Sipthorp and Misson (2009) found that sample attrition is related to length of residence, but these and other variables associated with residential mobility have been integrated for the computation of longitudinal weights in LSAC that we use in the bivariate analysis.

To assess longitudinal associations, we additionally restrict the sample to children who participated in more than one survey wave, and to children's observations with non-missing information on academic performance items collected in third, fifth' and seventh grade. Missing data in academic performance involves $29 \%$ of third graders, and about $10 \%$ of fifth and seventh graders. Since the administration of academic performance tests available in LSAC (see more detail below) started in 2008 , approximately $23 \%$ of respondents of LSAC-K who did third grade in 2007 have no available information on academic performance because no test was administered to them. Remaining sources of missingness are test absences related to illness or other accepted reasons, non-consent of parents to access the data, or lack of data match by the state/territory jurisdiction. Following standard practice, missing values of the dependent variable were not imputed and cases with missing information on academic performance were deleted. In sensitivity analyses (available under request) of multivariate models, we contrasted results of the analysis presented in the results section with an alternative analysis that included only children with no missing observations. We did not find substantively different results. The analytical sample contains 3,481 children and 8,609 observations.

The inspection of model covariates (i.e. independent variables in regression analyses) revealed trivial levels of missing data. Less than $10 \%$ of cases had a missing value in a model covariate, and less than $5 \%$ had more than one missing value in a model covariate. To minimise observation loss we imputed missing information of model covariates applying multiple imputations for chained equations (MICE) and using information of all model covariates for the imputations, to create 20 imputed datasets using the MICE command in Stata 14.0 (Royston \& White, 2011). The imputation procedure resulted in successful imputations for all cases with missing values.

\section{Measures}

\section{Academic test scores}

To assess school performance we use measures of academic skills in literacy and numeracy for children of different ages. This includes tests scores from The National Assessment Program - Literacy and Numeracy (NAPLAN), which is a national test conducted annually since 2008 and administered to nearly all Australian students in school grades 3, 5, 7 and 9 in reading, writing, spelling, grammar and punctuation, and numeracy (Daraganova, Edwards, \& Sipthorp, 2013). Students with significant intellectual disabilities and those with a language background other than English who arrived in Australia less than one year ago may be exempted from testing. NAPLAN test scores are reported using single scales to enable comparisons of results across year levels and over time. Test scores in each of the five domains of NAPLAN range from 0 to 1000 with 
a mean score of 500, but results are not comparable across domains.

For the analysis we use information on school grade 3,5 and 7 NAPLAN tests. The modal age is 8 , 10 , and 12 years for children taking NAPLAN tests in school grades 3, 5 and 7 respectively. Since predictors must be measured prior to responses, we note some limitations in the analysis of linked NAPLAN data in LSAC. First, while NAPLAN tests are administered nationwide, every year, in the second full week in May, LSAC main interviews take place from March to December every two years. Second, LSAC respondents of the same study cohort may sit the same school grade NAPLAN test in different calendar years. For instance, LSAC-K respondents may sit in school grade 5 NAPLAN tests in 2009, 2010 and 2011, while LSAC data collection takes place in 2008, 2010 and 2012.

To enable the longitudinal analysis of the determinants of school performance, information on the time of testing, test repeating, and age at time of testing are available in the linked NAPLAN data files. To ensure that predictors are measured prior to NAPLAN testing, we have assigned NAPLAN test scores to predictors of the most immediate survey wave prior to the test. As a result, test scores in year 2008 have been matched to predictors of wave 2 (2006), tests scores in years 2008, 2009 and 2010 have been matched to predictors of wave 3 (2008), and test scores in year 2010, 2011 and 2012 have been matched to predictors of wave 4 (2010). The time gap in months between the LSAC main survey time and the NAPLAN test ranges from 1 month to 25 months. In the analyses, NAPLAN tests scores of school grades 3, 5 and 7 are assigned to information collected in LSAC-K that correspond to children around average ages 6/7, 8/9 and 10/11, respectively. To assess the effect of different time gaps, we included in preliminary multivariate models a control variable for the calendar year of administration of NAPLAN test, but results remained unchanged.

We reduce the number of outcomes by means of factor analysis because scores on the five NAPLAN tests display high common correlation (overall Cronbach alpha $=.936)$. The results of the factor analysis with varimax rotation indicate that only one factor captures common variation among the five scores (eigenvalue $=3.708$ ). The standardised factor - NAPLAN score - ranges from -3.33 to 3.01 and has a mean value approximate to 0 and a standard deviation approximate to 1 . Thus, the NAPLAN score takes negative values for scores below the grand mean and positive values for scores above the grand mean across grade 3, 5 and 7 NAPLAN tests ${ }^{1}$.

\section{Residential relocations}

LSAC collects relevant measures for building detailed residential histories of children at each wave, with information since last interview (or since birth in wave 1) on relocation occurrence, region of residence, recency of latest relocation before interview date, and number of lifetime relocations. Unfortunately, reason for move is not available.

To address the impact of frequent mobility, we construct two indicators of cumulative frequency of lifetime relocations at each survey wave for moderate frequency (coded 1 if child did 1 or 2 relocations, coded 0 otherwise) and high frequency (coded 1 if child did 3 or more relocations, coded 0 otherwise). Research cited above showed that 1 or 2 relocations over children's life course has negligible impacts on children's cognitive abilities. We combine three and higher order moves in one category because this is how research has often defined frequent mobility (Jelleyman \& Spencer, 2008) and very few children in our sample move more than four or five times. Relocation distance is measured in two cumulative indicators for 'shortdistance relocations (coded 1 if moved within Local Government Areas coded 0 otherwise) and for longdistance relocations (coded 1 if moved across Local Government Areas $^{2}$, coded 0 otherwise). If both short-distance and long-distance relocations occurred since the last interview (or before first interview), then both indicators take a value 1 .

Relocation age-stage can be coded for four age groups: before school age (i.e. before age $4 / 5$ ), by school start (i.e. between age $4 / 5$ and age 6/7), between age $6 / 7$ and age $8 / 9$, and between age $8 / 9$ and age 10/11. We disregard moves that occur between age 10/11 and age 12/13 because we do not know with certainty if a move has occurred before NAPLAN test administration for seventh graders, the last observation of school performance we observe. To address contemporaneous associations, capturing associations where relocations occurred in the most immediate agespecific stage before taking the test, we construct three indicators: the first is coded 1 if relocation occurred between age $4 / 5$ and age $6 / 7$ for observations of grade 3 , the second is coded 1 if 
relocation occurred between age $6 / 7$ and age $8 / 9$ for observations of grade 5 , and the third is coded 1 if relocation occurred between age $8 / 9$ and age 10/11 for observations of grade 7. To address cumulative associations, we construct three indicators: the first is coded 1 if relocation occurred before age $4 / 5$ for all observations, the second is coded 1 if relocation occurred between age $4 / 5$ and age $6 / 7$ for observation of grades 5 and 7 , and the third is coded 1 if relocation occurred between age $6 / 7$ and age $8 / 9$ for observation of grade 7 .

It is worth noting that most children in our sample moved by age $10 / 11$. About $26 \%$ did not move, $31 \%$ moved before reaching school age and $43 \%$ moved during school age.

\section{Covariates}

We include a number of covariates measured prior to NAPLAN testing that are known correlates of residential relocations and academic performance. We divide them among those that stem from the family and home environments, those from the residential environment, and those from the school context. Family covariates include two family structure indicators for one biological parent structure and for step-parent structure (ref. two biological parents), number of under-age children in household (for two or three children, and four or more children; ref. only one child), maternal age in years, maternal education indicator (coded 1 if completed secondary education by the first interview, coded 0 otherwise), and maternal non-employment (coded 1 if the mother is nonemployed ${ }^{3}$, coded 0 otherwise). Additionally, a tight financial situation has been found to affect children's school performance. For this reason we include a poor household indicator (coded 1 if household income is less than $50 \%$ of median household income, coded 0 otherwise). An unclean and crowded home restricts cognitive development and for that reason home environment covariates include an indicator of household crowding (number of residents divided by number of bedrooms in the dwelling), the interviewer observations of the internal condition of the dwelling (coded 1 if all visible rooms of the household were not reasonably uncluttered, coded 0 otherwise). To address the impacts of the residential environment, we include as covariates the Socio-Economic Index For Areas (SEIFA) advantage/disadvantage score divided by 100 , an indicator for perceived bad neighbourhoods (i.e. the respondent parent's perception of whether the neighbourhood is a good place to bring up children: coded 1 if yes, coded 0 if no), and an indicator of residence in an urban area (coded 1 if yes, coded 0 if no). Characteristics of the school environment include an indicator of whether the child has attended more than one school (coded 1 if yes, coded 0 if no), an indicator of teacher's response on child's frequent school absences (coded 1 if yes, coded 0 if no), and an indicator of teacher's opinion about whether parents are involved with the school (coded 1 if yes, coded 0 if no). We also include additional demographic and (pre-school) child characteristics. These covariates included child's birth weight percentile, age in months, gender, country of birth (indicator coded 1 if non-Australian born, coded 0 otherwise), indigenous background (indicator coded 1 if indigenous background, coded 0 otherwise). Table $A 1$ in the online appendix presents summary statistics for all model covariates.

\section{Analytical strategy}

After the description of NAPLAN test score averages by school grade and relocation circumstance (table 1), our analytical strategy combines two types of panel data methods to address longitudinal, multivariate associations: hybrid regression and random coefficient regression models.

First we estimate hybrid panel regression models (Allison, 2009) to address the question of whether relocations (i.e. occurrence, distance, and frequency) impact children's school performance (table 2). The hybrid panel model is an extension of multivariate regression models that leverage the longitudinal structure of the data by partitioning the overall variation of the association under study in between- and within-subject variation. The method consists of the estimation of randomeffects regression models adding group-mean deviated variables of time-varying covariates in the models. By adding group-mean deviated variables of the covariates in the model, the assumption in random-effects models that the random term is uncorrelated with the covariates is relaxed. Additionally, the coefficients of the group-mean deviated variables can be interpreted as withinsubject variation, and the coefficients of the original variables can be interpreted as between-subject variation. By between-subject variation we refer to average differences in school performance across 
children. The between-subject analysis enables conclusions on whether school performance is associated with group-differences in the family home and residential environments of those who move and those who stay. By within-subject variation we refer to changes within children in school performance before and after the relocation. The within-subject analysis allows conclusions about the impacts of relocations by comparing the average school performance in periods before and after relocations. An additional advantage of hybrid panel regression models is that time-invariant selective factors or traits of children are cancelled out in the model specification, as in fixed-effects models.

Second, we estimate random coefficient regression models to address the question of the contemporaneous and cumulative impacts of agespecific relocations on progress in school performance (table 3 ). Random coefficients models are extensions of multivariate regression models that, leveraging the longitudinal structure of the data, relax the assumption that all study subjects follow the same average trajectory, e.g. a steady increase in academic performance (Bliese \& Ployhart, 2002). To relax this assumption, we define a model with a random intercept and a random coefficient for age. This model resembles a basic growth model, where each child's school performance may start at a different level and depart from the average progress. Measures for age-specific relocations representing contemporaneous effects of relocations, as described in the measures section, were included in the model. Significant associations of the contemporaneous age-specific indicators will shed light on the relocation ages with immediate impacts on academic progress. The cumulative impact of age-specific relocation is captured by three indicators noted in the measures section. Significant associations of the cumulative age-specific indicators will shed light on the relocation ages that have sustained or later impacts in academic progress.

To identify factors that influence the abovementioned associations, we estimate several models where we add other covariates to model specifications in a sequential fashion. In a first model specification, we only control for demographic variables and children's infancy indicators. In the second model we add to the first model specification controls for family structure and socio-economic status. In the third model we add to the first model specification controls for the residential environments, including characteristics of the peer, neighbourhood, and school context. In the fourth model we include all sets of control variables. Variations in the significance and the strength of the relocation coefficients can be used as an indication of the type of factors that more likely affect the association between relocations and school performance.

\section{Results}

Table 1 presents weighted means of standardised NAPLAN test scores by school grade and a number of characteristics of children's lifetime relocation experiences - children's age, distance and frequency. Detailed mean test scores for subject-specific tests can be consulted in table A2 in the online appendices. We show results for school grades 3, 5, and 7 as well as the progression between school grade 3 and 7 . Note that the average standardised test score increases across school grades because test results are reported using a single scale for all students in grades 3,5 and 7.

Results according to relocation characteristics in table 1 suggest certain association patterns that repeat across school grades. First, we find that children with early relocation experiences, since infancy up to pre-school (i.e. before age 4/5), have statistically significant worse average scores in all school grades than children who do not move in early stages. The consistent pattern across school grades hints at a possible sustainability of the impact of children's early experiences in later cognitive development. Test scores are also under the average for children who move at later stages, between ages $4 / 5$ to $8 / 9$, but the statistical significance of the association is largely marginal for school grade 5 and 7. Second, no substantively or statistically significant differences in test scores by relocation distance are found. Third, the largest mean differences in school performance observed in table 1 are those related to the frequency of relocation. Compared to grade-specific average test performance, children who relocate once or twice perform better, while children who relocate three or more times perform much worse. Mean differences are particularly significant, substantively 
Table 1. Means of standardised NAPLAN test scores by school grade and relocation characteristics

\begin{tabular}{llll} 
Grade 3 & Grade 5 & Grade 7 & Grade 7-Grade 3 \\
\hline
\end{tabular}

\begin{tabular}{|c|c|c|c|c|c|c|c|}
\hline Average & -0.85 & & 0.05 & & 0.63 & & 1.50 \\
\hline \multicolumn{8}{|l|}{ Age at relocation } \\
\hline before $4 / 5$ & -0.89 & $* *$ & 0.03 & $* *$ & 0.61 & $*$ & 1.50 \\
\hline $4 / 5$ to $6 / 7$ & -0.92 & $* *$ & 0.02 & $(*)$ & 0.60 & $(*)$ & 1.51 \\
\hline $6 / 7$ to $8 / 9$ & & & 0.01 & & 0.59 & $(*)$ & 1.50 \\
\hline $8 / 9$ to $10 / 11$ & & & & & 0.60 & & 1.52 \\
\hline \multicolumn{8}{|l|}{ Relocation distance } \\
\hline short distance & -0.87 & & 0.06 & & 0.64 & & 1.51 \\
\hline long distance & -0.89 & & 0.03 & & 0.62 & & 1.52 \\
\hline \multicolumn{8}{|l|}{ Relocation frequency } \\
\hline 1 to 2 relocations & -0.84 & & 0.08 & $(*)$ & 0.68 & $* *$ & $1.52 \quad(*)$ \\
\hline 3 or more relocations & -0.98 & $* * *$ & -0.01 & $*$ & 0.55 & $* * *$ & 1.49 \\
\hline
\end{tabular}

Source: LSAC-K (2004-2012). Significance tests for mean differences between relocation characteristics and their absence. $\left({ }^{*}\right)=p<0.1 ;{ }^{*}=p<0.05 ;{ }^{* *}=p<0.01 ; * * *=p<0.001$

and statistically, for the children who relocate three or more times, and suggest a non-linear association between relocation frequency and school performance.

Regarding performance progress in NAPLAN tests from grades 3 to 7 , we find very small and largely insignificant differences in table 1 . This result is a preliminary indication that school performance trajectories are not importantly altered by relocation events. If the performance growth rate is the same despite differences in initial levels, then relocations might be leading towards neither convergence nor divergence in school performance. Our next step is to test whether these associations remain in a multivariate setting.

\section{Relocation distance and frequency}

Table 2 displays selected results (and table A3 in the online appendix displays full results) of the hybrid regression models that address the multivariate associations of relocation distance and frequency with differences in school performance across children who move and who stay (betweensubject effects) and changes in school performance before and after a relocation (within-subject effects). Model 1 in table 2 included relocation variables (i.e. frequency and distance) and, additionally, controlled for age and other characteristics of children. Results from model 1 indicate that some relocation characteristics are only related to average performance differences between children, only related to changes in school performance after relocations, or unrelated with school performance. More specifically, we find a statistically significant between-effect of relocation frequency $(b=-.155, p>$.001) where children moving three or more times perform worse than children who do not move. We also find a positive withineffect of long-distance relocations $(b=.089, p>.01)$, where children do slightly improve their academic performance after moving across regional boundaries. We find no significant between- or within-effect for moderate relocation levels on school performance. Overall, the size of the effects in model 1 is modest, below .2 standard deviations. In contrast, other model variables such as age or indigenous origin have larger effects that exceed .2 or .5 standard deviations, respectively.

In models 2, 3 and 4 of table 2, we add to model 1 characteristics of the family and home environment, the residential environment, and the school environment, respectively. Comparing results of these models to those of model 1 , we observe a few changes in coefficients' size and statistical significance. First, the significant negative between-effect of relocation frequency vanishes 
Table 2. Between- and within-subject differences in school performance (selected results)

\begin{tabular}{|c|c|c|c|c|c|}
\hline & $\begin{array}{l}\text { Model } 1 \\
\text { Baseline } \\
\text { controls }\end{array}$ & $\begin{array}{c}\text { Model } 2 \\
\text { Family/home } \\
\text { controls }\end{array}$ & $\begin{array}{l}\text { Model } 3 \\
\text { Residential } \\
\text { controls }\end{array}$ & $\begin{array}{l}\text { Model } 4 \\
\text { School } \\
\text { controls }\end{array}$ & $\begin{array}{l}\text { Model } 5 \\
\text { All } \\
\text { controls }\end{array}$ \\
\hline \multicolumn{6}{|c|}{ Differences across children (between-subject differences) } \\
\hline No relocation & Ref. & Ref. & Ref. & Ref. & Ref. \\
\hline \multirow[t]{2}{*}{1 or 2 relocations } & 0.024 & $0.064^{*}$ & 0.007 & 0.048 & $0.055^{*}$ \\
\hline & [0.03] & {$[0.03]$} & [0.03] & [0.03] & [0.03] \\
\hline \multirow[t]{2}{*}{3 or more relocations } & $-0.155^{* *}$ & 0.022 & $-0.131 * *$ & -0.078 & 0.022 \\
\hline & {$[0.05]$} & [0.05] & {$[0.05]$} & [0.05] & [0.05] \\
\hline \multirow[t]{2}{*}{ Long-distance relocation } & -0.027 & -0.018 & -0.002 & -0.012 & 0.009 \\
\hline & [0.04] & [0.04] & {$[0.04]$} & {$[0.04]$} & [0.04] \\
\hline \multicolumn{6}{|c|}{ Changes in children overtime (within-subject differences) } \\
\hline No relocation & Ref. & Ref. & Ref. & Ref. & Ref. \\
\hline \multirow[t]{2}{*}{1 or 2 relocations } & 0.035 & 0.034 & 0.038 & 0.033 & 0.034 \\
\hline & {$[0.03]$} & [0.03] & [0.03] & [0.03] & [0.03] \\
\hline \multirow[t]{2}{*}{3 or more relocations } & 0.037 & 0.036 & 0.038 & 0.034 & 0.035 \\
\hline & [0.03] & [0.03] & [0.03] & {$[0.03]$} & [0.03] \\
\hline \multirow[t]{2}{*}{ Long-distance relocation } & $0.089 * *$ & $0.086^{*}$ & $0.094^{* *}$ & $0.088^{*}$ & $0.089 *$ \\
\hline & {$[0.03]$} & {$[0.03]$} & {$[0.03]$} & {$[0.03]$} & {$[0.03]$} \\
\hline Subjects & 3,481 & 3,481 & 3,481 & 3,481 & 3,481 \\
\hline Subject-observations & 8,609 & 8,609 & 8,609 & 8,609 & 8,609 \\
\hline
\end{tabular}

Notes: Hybrid panel regression models. Coefficients can be interpreted as standard deviation change. Standard errors in square brackets under coefficients. Control variables (measured prior to NAPLAN testing) - All models include children's gender, age in months, age-squared, indigenous background, non-Australian born, birth weight percentile. Model 2 includes one biological parent, step-family, two or three/four or more under-age children in household, maternal age, mother completed secondary education, mother is non-employed, and poor household. Model 3 includes a house crowding indicator, cluttered house, SEIFA index, negative neighborhood perception, and urban area. Model 4 includes school change, absenteeism, and parents' school involvement. Model 5 includes all covariates mentioned before. $\left({ }^{*}\right)=p<0.1 ;{ }^{*}=$ $p<0.05 ;{ }^{* *}=p<0.01 ; * * *=p<0.001$

after controlling for characteristics of the family and home environment, and for those of school environments. This change might have been induced by the inclusion of characteristics associated with relocations and school performance - particularly those with relevant size effects such as absenteeism, parents' school involvement, and household structure - which are negatively correlated with school performance but positively correlated with frequent relocations. Second, we find marginal positive statistical significance for a between-effect of moderate relocation levels after controlling for characteristics of the family and home environments. The inclusion of characteristics associated with relocations and school performance - particularly those with relevant size effects such as poor household, lone parent or step-family might suggest that average performance of children is better among those who relocate, but not frequently, compared to those who do not relocate.

In model 5 of table 2 , we add to model 1 all additional covariates of models 2, 3 and 4, and thus, it is a fully specified model. Results of model 5 are similar to those of prior models, and thus, 
interpretations of the associations between relocations and school performance remain unchanged. We note that other coefficients in model 5 for covariates on situations and contexts in the family, place of residence and school matter for children's school performance more than relocations per se (see table $\mathrm{A} 3$ in appendix). Factors associated with more than one standard deviation difference in school performance include pre-exiting situations (between-effects) such as non-intact families, school absenteeism, and indigenous background - for negative associations as well as mother's education, relative socioeconomic advantage of the area of residence, parents' school involvement, female child, and nonAustralian background - for positive associations.

\section{Age-specific relocations}

Selected results of the random coefficients models are presented in table 3 (full results are available in table A4 in the online appendix). These models include variables that address the impacts of age-specific relocations before tests in grades 3 , 5 and 7 took place (contemporaneous associations) as well as the persistence of the effect of agespecific relocations in later school stages (cumulative associations). The pattern of results was very similar across model specifications, and for that reason we only show model 1 , with the baseline specification, and model 5 , the fully specified model. Overall, we find neither substantive nor statistically significant effects of the age stage when relocations occur on school performance trajectories. In model 1, which additionally controls for children's characteristics, an individual random effect, and a random coefficient for age, coefficients of age-specific relocations were close to 0 and mostly statistically insignificant. Only relocations occurring at the time of school entry (i.e. between age $4 / 5$ and age 6/7) have marginally significant and small contemporaneous impacts during grade $3(b=-.083$, $p>$.01). Further, persistence of negative effects of early relocations on school performance in later stages that could be interpreted from the bivariate associations in table 1 do not hold in the multivariate models, since the coefficients for cumulative associations of age-specific relocations are largely insignificant. In the fully specified model 5 , the modest immediate impact of relocations occurring at the time of school entry remains statistically significant at the margin, though. We note that controlling for age and age squared in the model renders insignificant and small coefficients not only for age-specific relocation variables, but also for the random coefficient of age, which suggests that children follow similar patterns of growth in NAPLAN test performance overtime. Coefficients for other model covariates are similar to those described before. Overall, these results suggest that developmental stage at relocation has little effect on school performance trajectories measured as repeated participations in NAPLAN tests in grades 3,5 and 7.

\section{Discussion}

In this study, we have examined the associations between relocations, from infancy to middle childhood, and school performance in school grades 3, 5 and 7 using recent data from the Longitudinal Study of Australian Children. We argued that the associations between childhood relocations and school performance are complex and highly dependent on the intersections between relocation biographies (i.e. relocation lifetime frequency, distance, and developmental age-stage) and the proximal contexts where children are embedded (i.e. family, home, and school).

Some key findings arise from our study. First, our analyses confirm for the Australian case that, under certain conditions, residential relocations are associated with school performance. In line with studies from the US context, the associations we find can be considered modest, since the largest differences we found are around 0.2 standard deviations between those who relocate and those who do not. To put this in perspective, we find that differences among children who experience changes in family structure across survey waves are around 0.6 standard deviations.

Second, we have some evidence of a non-linear association between relocation frequency and school performance. We find that children who relocate often (3 or more times) display worse school performance, while children who relocate moderately (1-2 times) display better school performance. Using hybrid panel regression models, we further examined these associations as differences in school performance between subjects (between-effects) and changes in school 
Table 3. Effects of age-specific relocations on school performance trajectories (selected results)

\begin{tabular}{lcc}
\hline & Model 1 & Model 5 \\
\cline { 2 - 3 } Contemporaneous association & & \\
Move between ages 4/5 to 6/7 (on grade 3) & $-0.036^{* *}$ & $-0.034^{*}$ \\
& {$[0.02]$} & {$[0.03]$} \\
Move between ages 6/7 to 8/9 (on grade 5) & -0.014 & 0.011 \\
& {$[0.02]$} & {$[0.02]$} \\
Move between ages 8/9 to 10/11 (on grade 7) & -0.002 & -0.002 \\
& {$[0.02]$} & {$[0.02]$} \\
\hline Cumulative association & & \\
Before age 4/5 & -0.038 & -0.007 \\
& {$[0.03]$} & {$[0.02]$} \\
Ages 4/5 to 6/7 & -0.048 & 0.009 \\
& {$[0.03]$} & {$[0.03]$} \\
Ages 6/7 to 8/9 & -0.014 & 0.004 \\
& {$[0.02]$} & {$[0.02]$} \\
\hline Subjects & 3,481 & 3,481 \\
Subject-observations & 8,609 & 8,609 \\
\hline
\end{tabular}

Notes: Random-coefficient regression models. Coefficients can be interpreted as standard deviation change. Standard errors in square brackets under coefficients. Control variables (measured prior to NAPLAN testing) - All models include children's gender, age in months, age-squared, indigenous background, non-Australian born, birth weight percentile. Model 5 additionally includes one biological parent, step-family, two or three/four or more under-age children in household, maternal age, mother completed secondary education, mother is non-employed, poor household, house crowding indicator, cluttered house, SEIFA index, negative neighborhood perception, urban area, school change, frequent absenteeism, and parents' school involvement. $\left({ }^{*}\right)=p<0.1 ;{ }^{*}=p<0.05 ;{ }^{* *}=p<0.01 ;{ }^{* * *}=p<0.001$

performance within subjects (within-effects). We found that the significant associations related only to differences between children who moved and who stay put, and not to changes in school performance before and after the relocation. This suggests that these associations are rather more likely to be due to pre-existing differences among children who relocate than due to direct impacts of relocations. On the one hand, children who relocate moderately may be found in family and home contexts that provide opportunities. On the other hand, children who relocate frequently may be found in contexts with high concentrations of disadvantage, with residential insecurity one possible source. In support of this thesis, we find that after controlling for detrimental family and home characteristics for children's school performance, the negative effects of frequent relocations vanish, and the positive effects of moderate relocation levels increase. It is worth noting that children's frequent relocation levels in our sample were associated with parents' employment status change and, particularly, with changes in parental partnership status (i.e. separation and re-partnering) that often have negative impacts on children. Third, our multivariate results show that long-distance relocations were modestly associated with improvements in school performance after relocations. The result contradicts the idea that relocations over longer distances break proximal environments and preclude children from the benefits of enduring connections with peers, the community, and the school environment. However, long-distance relocations are often motivated by positive changes, such as parental careers or neighbourhood improvements that indicate better conditions for children's cognitive development. In fact, children who relocate over long distances in our sample are likely to move to better 
neighbourhoods and have continuously employed fathers.

Last, we examined the associations between the relocation age-patterns and school performance trajectories. Bivariate analyses showed that early childhood moves are associated with slightly but persistently lower school performances across school grades. However, we did not find evidence of a sustained negative effect of early-age relocations throughout primary school performance in the multivariate random coefficient models that captured typical developmental growth curves.

In conclusion, our findings suggest that the associations of relocations with cognitive ability and development are imbued in the biographical and social context of childhood relocations. These findings are consistent with those of recent studies grounded on life course theory and methods, but resting on less sophisticated sets of analyses (e.g. Gambaro \& Joshi 2016; Beck, Buttaro \& Lennon, 2016). While changing residence is not per se a major determinant of academic performance, the contexts and environment where children are embedded matter. Since relocations that are detrimental for academic performance are embedded in contexts of disadvantage, policies aimed at supporting disadvantaged families may widely benefit children's cognitive development. Recent research on factors that mitigate the observed negative outcomes among frequent movers also finds that skills and competencies linked to children's resilience work better when only a few risk factors are present at a time (McLeod, Heriot, \& Hunt, 2008).

Although we addressed a number of relevant measures of children's relocation histories, several questions about the underlying associations remain unanswered. Particularly, our study has emphasised the role of accumulation of relocation experience at the expense of attention to the continuity or change in contexts of disadvantage upon relocation. Recent literature underscored the importance of processes such as segregation and concentration of disadvantage as drivers of persisting inequalities among children (e.g. Hamnett, Ramsden \& Butler, 2007; Clark \& Maas 2012). Our models only adjusted for a number of socio-economic context features that significantly affected children's academic performance, such as the SEIFA indicator for area disadvantage as well as an indicator of the parent's perception about the neighbourhood. An initial exploration of changes in SEIFA values upon relocation showed that when children move, they often move to better socio-economic contexts. Only $10 \%$ relocate to more disadvantaged areas, often these being children who moved three or more times. We do not find significant associations between changes in SEIFA and academic performance, though. However, we believe that further research needs to address whether and how persistence (more than change) in (dis)advantaged areas impacts children's wellbeing and development.

Another question that arises from our research is whether the weak associations between relocations and school performance could be inferred as a population pattern, or whether these associations are moderated by socio-economic strata. An initial exploration showed neither substantive nor statistically significant associations of interaction terms between relocation indicators and household economic status. Further research is required to address other potential interaction effects. We also note that despite the number of sensitivity tests we performed, our results may not be completely accurate due to analytical limitations, such as the different calendars of data collection of LSAC (every two years, from March to December) and NAPLAN tests (each year, May), as well as a somewhat biased sample towards less disadvantaged families. Last, as with most prior studies on the topic, we did not have information on the motivations for household relocations, the assessment of which can provide additional, nuanced evidence to inform effective policy intervention in the field (Lennon et al., 2016). However, this is not necessarily an issue since our models adjust for variables that capture situations of disadvantage often associated with negative reasons for relocation so as to provide adequate estimates of typical relocation impacts.

Despite the limitations, this study makes substantive and methodological contributions to the literature. Our study contributes to an emerging body of research, largely focused on the US context, by examining longitudinal associations between residential moves and academic performance in the Australian context. We did not find the associations to differ much to those of US-based research, despite the relatively more equal opportunity to access high-quality early education and lower poverty levels among Australian children. Our study 
also makes a contribution by furthering the diachronic assessment of the associations between academic performance and residential histories, using analytical models and measures that acknowledge the biographical aspects of the association, as well as potential sources of time- constant unobserved heterogeneity. Ours is one of the few studies that leverages longitudinal data to disentangle whether any observed associations are the result of relocations, or are due to pre-existing characteristics of children who relocate. We call for further research along these lines.

\section{Acknowledgements}

This research was supported by the Australian Research Council (ARC) Centre of Excellence for Children and Families over the Life Course (project number CE140100027), and by the Spanish Ministry of Economy, Industry and Competitiveness (grant number RYC-2015-18254). This paper uses unit record data from Growing Up in Australia, the Longitudinal Study of Australian Children (LSAC) Survey. The study is conducted in partnership between the Department of Social Services (DSS), the Australian Institute of Family Studies (AIFS) and the Australian Bureau of Statistics (ABS). The views expressed in this report are those of the authors alone and do not represent those of DSS, AIFS, the ABS or DEEWR.

\section{References}

Ackerman, B. P., Kogos, J., Youngstrom, E., Schoff, K., \& Izard, C. (1999). Family instability and the problem behaviors of children from economically disadvantaged families. Developmental psychology, 35(1), 258-268. https://doi.org/10.1037/0012-1649.35.1.258

Adam, E. K., \& Chase-Lansdale, P. L. (2002). Home sweet home(s): parental separations, residential moves, and adjustment problems in low-income adolescent girls. Developmental psychology, 38(5), 792805. https://doi.org/10.1037/0012-1649.38.5.792

Allison, P. D. (2009). Fixed-Effects Regression Models. Thousand Oaks, CA: Sage Publications. https://doi.org/10.4135/9781412993869

Anderson, S., Leventhal, T., Newman, S., \& Dupéré, V. (2014). Residential Mobility Among Children: A Framework for Child and Family Policy. Cityscape, 16(1), 5-36.

Astone, N. M., \& McLanahan, S. S. (1994). Family structure, residential mobility, and school dropout: A research note. Demography, 31(4), 575-584. https://doi.org/10.2307/2061791

Australian Council of Social Service (2014). The Poverty Report 2014.

Beck, B., Buttaro Jr, A., \& Lennon, M. C. (2016). Home moves and child wellbeing in the first five years of life in the United States. Longitudinal and Life Course Studies, 7(3), 240-264. https://doi.org/10.14301/llcs.v7i3.374

Bliese, P. D., \& Ployhart, R. E. (2002). Growth modeling using random coefficient models: Model building, testing, and illustrations. Organizational Research Methods, 5(4), 362-387. https://doi.org/10.1177/109442802237116

Bradley, R. H., \& Corwyn, R. F. (2002). Socioeconomic status and child development. Annual review of psychology, 53(1), 371-399. https://doi.org/10.1146/annurev.psych.53.100901.135233

Bronfenbrenner, U., \& Morris, P. A. (2006). The bioecological model of human development. In R. M. Lerner and W. Damon (Eds.), Handbook of child psychology Vol 1 (pp. 793-828). Hoboken, NJ: John Wiley \& Sons, Inc.

Clark, W. A., \& Maas, R. (2012). Schools, neighborhoods and selection: outcomes across metropolitan Los Angeles. Population Research and Policy Review, 31(3), 339-360. https://doi.org/10.1007/s11113-012-9234-9

Clark, W., \& Maas, R. (2016). Spatial mobility and opportunity in Australia: Residential selection and neighbourhood connections. Urban Studies, 53(6), 1317-1331. https://doi.org/10.1177/0042098015572976

Coley, R. L., Leventhal, T., Lynch, A. D., \& Kull, M. (2013). Relations between housing characteristics and the well-being of low-income children and adolescents. Developmental psychology, 49(9), 1775. https://doi.org/10.1037/a0031033 
Coley, R. L., \& Kull, M. (2016). Cumulative, Timing-Specific, and Interactive Models of Residential Mobility and Children's Cognitive and Psychosocial Skills. Child Development, 87(4), 1204-1220. https://doi.org/10.1111/cdev.12535

Crowder, K., \& South, S. J. (2003). Neighborhood distress and school dropout: The variable significance of community context. Social Science Research, 32(4), 659-698. https://doi.org/10.1016/S0049-089X(03)00035-8

Crowder, K., \& Teachman, J. (2004). Do residential conditions explain the relationship between living arrangements and adolescent behavior? Journal of Marriage and Family, 66(3), 721-738. https://doi.org/10.1111/j.0022-2445.2004.00049.x

Daraganova, G., Edwards, B., \& Sipthorp, M. (2013). Using National Assessment Program Literacy and Numeracy (NAPLAN) Data in the Longitudinal Study of Australian Children (LSAC). Department of Families, Housing, Community Services and Indigenous Affairs.

Ersing, R. L., Sutphen, R., \& Loeffler, D. N. (2009). Exploring the impact and implications of residential mobility: From the neighborhood to the school. Advances in Social Work, 10(1), 1-18.

Evans, G. W., \& Wachs, T. D. (2010). Chaos and its influence on children's development. Washington, DC: American Psychological Association.

Gambaro, L., \& Joshi, H. (2016). Moving home in the early years: what happens to children in the UK? Longitudinal and Life Course Studies, 7(3), 265-287. https://doi.org/10.14301/Ilcs.v7i3.375

Gasper, J., DeLuca, S., \& Estacion, A. (2010). Coming and going: Explaining the effects of residential and school mobility on adolescent delinquency. Social Science Research, 39(3), 459-476. https://doi.org/10.1016/j.ssresearch.2009.08.009

Gray, M., \& Sanson, A. (2005). Growing up in Australia: the longitudinal study of Australian children. Family Matters, (72), 4.

Hamnett, C., Ramsden, M., \& Butler, T. (2007). Social background, ethnicity, school composition and educational attainment in East London. Urban Studies, 44(7), 1255-1280. https://doi.org/10.1080/00420980701302395

Haveman, R., Wolfe, B., \& Spaulding, J. (1991). Childhood events and circumstances influencing high school completion. Demography, 28(1), 133-157. https://doi.org/10.2307/2061340

Herbers, J. E., Cutuli, J. J., Supkoff, L. M., Heistad, D., Chan, C. K., Hinz, E., \& Masten, A. S. (2012). Early reading skills and academic achievement trajectories of students facing poverty, homelessness, and high residential mobility. Educational Researcher, 41(9), 366-374. https://doi.org/10.3102/0013189X12445320

Huinink, J., Vidal, S., \& Kley, S. (2014). Individuals' openness to migrate and job mobility. Social science research, 44, 1-14. https://doi.org/10.1016/i.ssresearch.2013.10.006

Ingersoll, G. M., Scamman, J. P., \& Eckerling, W. D. (1989). Geographic mobility and student achievement in an urban setting. Educational Evaluation and Policy Analysis, 11(2), 143-149. https://doi.org/10.3102/01623737011002143

Jelleyman, T., \& Spencer, N. (2008). Residential mobility in childhood and health outcomes: a systematic review. Journal of Epidemiology and Community Health, 62(7), 584-592. https://doi.org/10.1136/jech.2007.060103

Joshi, H., Gambaro, L., Mostafa, T., Lupton, R., Lennon, M.C., Buttaro, A., \& Beck, B. (2015). 'Moving home in the early years: Family and child outcomes in the UK and US.' Centre for Longitudinal Studies.

Lawrence, E., Root, E. D., \& Mollborn, S. (2015). Residential mobility in early childhood: Household and neighborhood characteristics of movers and non-movers. Demographic research, 33, 939. https://doi.org/10.4054/DemRes.2015.33.32

Lennon, M. C., Clark, W. A., \& Joshi, H. (2016). Residential mobility and wellbeing: exploring children's living situations and their implications for housing policy. Longitudinal and Lifecourse Studies, 7(3), 197200. https://doi.org/10.14301/llcs.v7i3.393

Maguire, B., Edwards, B., \& Soloff, C. (2012). Housing characteristics and changes across waves. Annual statistical report 2011, 67-77. 
McLeod, C., Heriot, S., \& Hunt, C. (2008). Changing places: Resilience in children who move. Australian Journal of Education, 52(2), 168-182. https://doi.org/10.1177/000494410805200205

Mehana, M., \& Reynolds, A. J. (2004). School mobility and achievement: A meta-analysis. Children and Youth Services Review, 26(1), 93-119. https://doi.org/10.1016/j.childyouth.2003.11.004

Moen, P. E., Elder Jr, G. H., \& Lüscher, K. E. (1995). Examining lives in context: Perspectives on the ecology of human development. Washington, DC, US: American Psychological Association. https://doi.org/10.1037/10176-000

OECD (2017). Income Distribution and Poverty. Retrieved on October 2 from https://stats.oecd.org/Index.aspx?DataSetCode=IDD

Pettit, B., \& McLanahan, S. (2003). Residential Mobility and Children's Social Capital: Evidence from an Experiment. Social Science Quarterly, 84(3), 632-649. https://doi.org/10.1111/1540-6237.8403009

Pribesh, S., \& Downey, D. B. (1999). Why are residential and school moves associated with poor school performance? Demography, 36(4), 521-534. https://doi.org/10.2307/2648088

Rasmussen, A. W., \& Stratton, L. S. (2012). How distance to a non-residential parent relates to child outcomes. IZA Discussion Paper No. 6965. Available at SSRN: http://ssrn.com/abstract=2170653

Royston, P., \& White, I. R. (2011). Multiple imputation by chained equations (MICE): implementation in Stata. Journal of Statistical Software, 45(4), 1-20. https://doi.org/10.18637/jss.v045.i04

Rumberger, R., \& Lim, S. A. (2008). Why students drop out of school: A review of 25 years of research. (Vol. 15, pp. 1-130). California Dropout Research Project Report.

Rumbold, A. R., Giles, L. C., Whitrow, M. J., Steele, E. J., Davies, C. E., Davies, M. J., \& Moore, V. M. (2012). The effects of house moves during early childhood on child mental health at age 9 years. BMC public health, 12(1), 583-594. https://doi.org/10.1186/1471-2458-12-583

Scanlon, E., \& Devine, K. (2001). Residential mobility and youth well-being: Research, policy, and practice issues. J. Soc. \& Soc. Welfare, 28, 119-138.

Schmitt, S. A., \& Lipscomb, S. T. (2016). Longitudinal associations between residential mobility and early academic skills among low-income children. Early Childhood Research Quarterly, 36, 190-200. https://doi.org/10.1016/j.ecresq.2016.01.002

Sipthorp, M., \& Misson, S. (2009). Wave 3 weighting and non-response. Australian Institute of Family Studies.

South, S. J., \& Haynie, D. L. (2004). Friendship networks of mobile adolescents. Social Forces, 83(1), 315-350. https://doi.org/10.1353/sof.2004.0128

Voight, A., Shinn, M., \& Nation, M. (2012). The longitudinal effects of residential mobility on the academic achievement of urban elementary and middle school students. Educational Researcher, 41, 385-392. https://doi.org/10.3102/0013189X12442239

Wood, D., Halfon, N., Scarlata, D., Newacheck, P., \& Nessim, S. (1993). Impact of family relocation on children's growth, development, school function, and behavior. JAMA, 270(11), 1334-1338. https://doi.org/10.1001/jama.1993.03510110074035

Ziol-Guest, K. M., \& McKenna, C. C. (2014). Early childhood housing instability and school readiness. Child development, 85(1), 103-113. https://doi.org/10.1111/cdev.12105

\section{Endnotes}

1. Only selected results of domain specific tests scores are presented in the text. Full results are available upon request.

2. Local government in Australia (LGA) is the lowest tier of government in Australia administered under the states and territories, which in turn are beneath the federal tier. There are currently 565 LGAs in Australia.

3. We note that most situations of non-employment in the household are mothers outside the labour force. Households with unemployed fathers are less than $2 \%$ of the sample. 


\section{Appendix}

Table A1. Univariate summary statistics

\begin{tabular}{|c|c|c|c|c|}
\hline & Mean & SD & Min. & Max. \\
\hline NAPLAN Test score: Reading & 504.312 & 94.177 & 0 & 842 \\
\hline NAPLAN Test score: Writing & 492.548 & 83.73 & 89 & 807.2 \\
\hline NAPLAN Test score: Spelling & 494.501 & 88.003 & 180 & 751.9 \\
\hline NAPLAN Test score: Grammar & 509.891 & 97.267 & 62 & 839 \\
\hline NAPLAN Test score: Numeracy & 499.606 & 90.211 & 0 & 848.4 \\
\hline NAPLAN Standardized score & 0.073 & 0.948 & -3.332 & 3.01 \\
\hline Short-distance relocations & 0.619 & 0.486 & 0 & 1 \\
\hline Long-distance relocations & 0.177 & 0.381 & 0 & 1 \\
\hline 1 or 2 relocations & 0.507 & 0.5 & 0 & 1 \\
\hline 3 or more relocations & 0.193 & 0.395 & 0 & 1 \\
\hline Relocated before age $4 / 5$ & 0.589 & 0.492 & 0 & 1 \\
\hline Relocated ages $4 / 5$ to $6 / 7$ & 0.257 & 0.437 & 0 & 1 \\
\hline Relocated ages $6 / 7$ to $8 / 9$ & 0.145 & 0.352 & 0 & 1 \\
\hline Relocated ages $8 / 9$ to $10 / 11$ & 0.064 & 0.245 & 0 & 1 \\
\hline Female & 0.493 & 0.5 & 0 & 1 \\
\hline Age & 8.807 & 1.655 & 6.25 & 11.667 \\
\hline Non-Australian born & 0.035 & 0.185 & 0 & 1 \\
\hline Indigenous & 0.024 & 0.154 & 0 & 1 \\
\hline Birth weight & 49.897 & 28.739 & 0.001 & 100 \\
\hline Two biological parents & 0.816 & 0.388 & 0 & 1 \\
\hline Lone parent & 0.129 & 0.335 & 0 & 1 \\
\hline Step family & 0.056 & 0.229 & 0 & 1 \\
\hline One child & 0.107 & 0.31 & 0 & 1 \\
\hline 2-3 children & 0.783 & 0.413 & 0 & 1 \\
\hline 4 or more children & 0.11 & 0.313 & 0 & 1 \\
\hline Poor household & 0.165 & 0.371 & 0 & 1 \\
\hline Maternal education & 0.82 & 0.384 & 0 & 1 \\
\hline Maternal non-employment & 0.243 & 0.429 & 0 & 1 \\
\hline Maternal age & 39.004 & 5.214 & 22 & 58 \\
\hline House crowding & 1.287 & 0.392 & 0.4 & 5 \\
\hline House cluttered & 0.053 & 0.225 & 0 & 1 \\
\hline SEIFA index & 10.128 & 0.746 & 5.9 & 12.1 \\
\hline Bad neighbourhood & 0.092 & 0.289 & 0 & 1 \\
\hline Urban area & 0.852 & 0.355 & 0 & 1 \\
\hline Absenteeism & 0.041 & 0.198 & 0 & 1 \\
\hline School change & 0.123 & 0.329 & 0 & 1 \\
\hline Parent' school involvement & 0.89 & 0.312 & 0 & 1 \\
\hline
\end{tabular}

Source: LSAC-K (2004-2010). Predictors are measured prior to NAPLAN testing (see methods section) 
Table A2. Means of standardised NAPLAN test scores and subject-specific test scores by school grade and relocation characteristics

\begin{tabular}{|c|c|c|c|c|c|c|c|c|c|c|c|c|}
\hline \multirow[b]{2}{*}{ Grade 3} & \multicolumn{2}{|l|}{ SD score } & \multicolumn{2}{|l|}{ Reading } & \multicolumn{2}{|l|}{ Writing } & \multicolumn{2}{|l|}{ Spelling } & \multicolumn{2}{|l|}{ Grammar } & \multicolumn{2}{|c|}{ Numeracy } \\
\hline & & & & & & & & & & & & \\
\hline Average & -0.85 & & 419.72 & & 427.15 & & 417.61 & & 426.68 & & 415.83 & \\
\hline \multicolumn{13}{|c|}{ Age at relocation } \\
\hline before $4 / 5$ & -0.89 & $* *$ & 415.44 & $* *$ & 424.57 & $*$ & 413.42 & $* *$ & 422.53 & $* *$ & 413.17 & $*$ \\
\hline $4 / 5$ to $6 / 7$ & -0.92 & $* *$ & 413.55 & $*$ & 422.86 & $(*)$ & 408.86 & $* * *$ & 418.80 & $* *$ & 411.57 & $(*)$ \\
\hline $6 / 7$ to $8 / 9$ & -1.02 & & 415.16 & & 401.44 & $*$ & 404.20 & & 409.84 & & 397.39 & $(*)$ \\
\hline \multicolumn{13}{|c|}{ Relocation distance } \\
\hline short distance & -0.87 & & 417.58 & & 426.22 & & 415.42 & & 425.27 & & 414.52 & \\
\hline long distance & -0.89 & & 418.98 & & 423.23 & & 412.42 & & 421.52 & & 414.81 & \\
\hline \multicolumn{13}{|c|}{ Relocation frequency } \\
\hline 1 to 2 & -0.84 & & 420.37 & & 427.33 & & 418.69 & & 427.05 & & 417.02 & \\
\hline 3 or more & -0.98 & $* * *$ & 408.09 & $* *$ & 418.33 & $*$ & 403.09 & $* * *$ & 414.94 & $* *$ & 405.73 & $* *$ \\
\hline \multicolumn{13}{|l|}{ Grade 5} \\
\hline Average & 0.05 & & 500.97 & & 491.39 & & 492.41 & & 510.27 & & 497.36 & \\
\hline \multicolumn{13}{|c|}{ Age at relocation } \\
\hline before $4 / 5$ & 0.03 & $* *$ & 498.56 & $*$ & 488.22 & $* *$ & 491.07 & & 506.67 & $* *$ & 494.55 & $* *$ \\
\hline $4 / 5$ to $6 / 7$ & 0.02 & $(*)$ & 498.75 & & 486.83 & $*$ & 488.48 & $(*)$ & 509.17 & & 492.99 & $*$ \\
\hline $6 / 7$ to $8 / 9$ & 0.01 & & 498.51 & & 487.73 & & 489.11 & & 505.10 & $(*)$ & 490.55 & $* *$ \\
\hline $8 / 9$ to $10 / 11$ & 0.03 & & 511.45 & & 473.58 & & 486.98 & & 502.46 & & 506.63 & \\
\hline \multicolumn{13}{|c|}{ Relocation distance } \\
\hline short distance & 0.06 & & 501.53 & & 490.89 & & 493.46 & & 511.08 & & 497.82 & \\
\hline long distance & 0.03 & & 500.81 & & 490.26 & & 488.70 & & 507.74 & & 492.23 & $(*)$ \\
\hline \multicolumn{13}{|c|}{ Relocation frequency } \\
\hline 1 to 2 & 0.08 & $(*)$ & 502.92 & & 493.37 & $*$ & 495.06 & $*$ & 512.27 & & 498.58 & \\
\hline 3 or more & -0.01 & $*$ & 497.28 & & 483.43 & $* * *$ & 486.47 & $*$ & 504.31 & $*$ & 491.76 & $*$ \\
\hline \multicolumn{13}{|l|}{ Grade 7} \\
\hline Average & 0.63 & & 553.51 & & 531.23 & & 548.39 & & 555.13 & & 550.72 & \\
\hline
\end{tabular}


Table A2. Continued.

\begin{tabular}{|c|c|c|c|c|c|c|c|c|c|c|c|c|}
\hline \multicolumn{13}{|c|}{ Age at relocation } \\
\hline before $4 / 5$ & 0.61 & $*$ & 551.85 & & 528.58 & $*$ & 546.90 & & 552.51 & $*$ & 547.50 & $* *$ \\
\hline $4 / 5$ to $6 / 7$ & 0.60 & $(*)$ & 550.87 & & 523.74 & & 547.10 & & 551.93 & $(*)$ & 546.91 & $(*)$ \\
\hline $6 / 7$ to $8 / 9$ & 0.59 & $(*)$ & 550.81 & & 529.98 & & 544.86 & & 550.08 & $*$ & 543.77 & $* *$ \\
\hline $8 / 9$ to $10 / 11$ & 0.60 & & 551.86 & & 530.82 & & 547.74 & & 549.77 & $(*)$ & 544.19 & $*$ \\
\hline \multicolumn{13}{|c|}{ Relocation distance } \\
\hline short distance & 0.64 & & 554.21 & & 530.71 & & 549.35 & & 555.27 & & 549.5 & \\
\hline long distance & 0.62 & & 553.36 & & 529.32 & & 544.98 & & 552.93 & & 549.97 & \\
\hline \multicolumn{13}{|c|}{ Relocation frequency } \\
\hline 1 to 2 & 0.68 & $* *$ & 557.18 & $* *$ & 533.74 & $*$ & 551.86 & $* *$ & 559.65 & $* *$ & 553.21 & $(*)$ \\
\hline 3 or more & 0.55 & $* * *$ & 547.54 & $* *$ & 524.67 & $* *$ & 543.38 & $*$ & 546.83 & $* * *$ & 542.57 & $* * *$ \\
\hline \multicolumn{13}{|c|}{ Grade 7 - Grade 3} \\
\hline Average & 1.50 & & 136.04 & & 102.39 & & 133.01 & & 133.40 & & 134.88 & \\
\hline \multicolumn{13}{|c|}{ Age at relocation } \\
\hline before $4 / 5$ & 1.50 & & 137.29 & & 100.78 & & 133.92 & & 132.98 & & 132.98 & $(*)$ \\
\hline $4 / 5$ to $6 / 7$ & 1.51 & & 137.72 & & 94.43 & $* *$ & 136.58 & $*$ & 134.79 & & 134.77 & \\
\hline $6 / 7$ to $8 / 9$ & 1.50 & & 137.59 & & 104.95 & & 133.24 & & 129.16 & & 132.9 & \\
\hline $8 / 9$ to $10 / 11$ & 1.52 & & 140.57 & $(*)$ & 104.21 & & 135.48 & & 131.64 & & 133.6 & \\
\hline \multicolumn{13}{|c|}{ Relocation distance } \\
\hline short distance & 1.51 & & 138.04 & $*$ & 101 & & 135.25 & $* *$ & 133.48 & & 134.54 & \\
\hline long distance & 1.52 & & 137.16 & & 102.28 & & 131.87 & & 135.86 & & 136.58 & \\
\hline \multicolumn{13}{|c|}{ Relocation frequency } \\
\hline 1 to 2 & 1.52 & $(*)$ & 137.49 & & 104.22 & & 134.61 & & 135.69 & & 135.14 & \\
\hline 3 or more & 1.49 & & 137.69 & & 96.88 & * & 135.06 & & 130.5 & & 132.34 & \\
\hline
\end{tabular}

Source: LSAC-K (2004-2010). Significance tests for mean differences between relocation characteristics and their absence.

$(*)=p<0.1 ; *=p<0.05 ;{ }^{* *}=p<0.01 ; * * *=p<0.001$ 
Table A3. Between- and within-subject differences in school performance (full models)

\begin{tabular}{|c|c|c|c|c|c|}
\hline & Model 1 & Model 2 & Model 3 & Model 4 & Model 5 \\
\hline \multicolumn{6}{|l|}{ Differences between individuals } \\
\hline No relocation & Ref. & Ref. & Ref. & Ref. & Ref. \\
\hline \multirow[t]{2}{*}{ Frequency: 1 or 2 relocations } & 0.024 & $0.064^{*}$ & 0.007 & 0.048 & $0.055^{*}$ \\
\hline & {$[0.03]$} & {$[0.03]$} & {$[0.03]$} & {$[0.03]$} & {$[0.03]$} \\
\hline \multirow[t]{2}{*}{ Frequency: 3 or more relocations } & $-0.155^{* *}$ & 0.022 & $-0.131 * *$ & -0.078 & 0.022 \\
\hline & {$[0.05]$} & {$[0.05]$} & {$[0.05]$} & {$[0.05]$} & {$[0.05]$} \\
\hline \multirow[t]{2}{*}{ Long-distance relocation } & -0.027 & -0.018 & -0.002 & -0.012 & 0.009 \\
\hline & {$[0.04]$} & {$[0.04]$} & {$[0.04]$} & {$[0.04]$} & {$[0.04]$} \\
\hline \multicolumn{6}{|l|}{ Differences within individuals } \\
\hline No relocation & Ref. & Ref. & Ref. & Ref. & Ref. \\
\hline \multirow[t]{2}{*}{ Frequency: 1 or 2 relocations } & 0.035 & 0.034 & 0.038 & 0.033 & 0.034 \\
\hline & {$[0.03]$} & {$[0.03]$} & {$[0.03]$} & {$[0.03]$} & {$[0.03]$} \\
\hline \multirow[t]{2}{*}{ Frequency: 3 or more relocations } & 0.037 & 0.036 & 0.038 & 0.034 & 0.035 \\
\hline & {$[0.03]$} & {$[0.03]$} & {$[0.03]$} & {$[0.03]$} & {$[0.03]$} \\
\hline \multirow[t]{2}{*}{ Long-distance relocation } & $0.089 * *$ & $0.086^{*}$ & $0.094 * *$ & $0.088^{*}$ & $0.089 *$ \\
\hline & {$[0.03]$} & {$[0.03]$} & {$[0.03]$} & {$[0.03]$} & {$[0.03]$} \\
\hline \multicolumn{6}{|l|}{ Other model covariates } \\
\hline \multirow[t]{2}{*}{ Female (between-effect) } & $0.198 * * *$ & $0.207^{* * *}$ & $0.204^{* * *}$ & $0.196 * * *$ & $0.207^{* * *}$ \\
\hline & {$[0.02]$} & {$[0.02]$} & {$[0.02]$} & {$[0.02]$} & {$[0.02]$} \\
\hline \multirow[t]{2}{*}{ Age (between-effect) } & $2.873 * * *$ & $2.365^{* * *}$ & $2.118^{* * *}$ & $2.691 * * *$ & $1.820 * *$ \\
\hline & {$[0.65]$} & {$[0.63]$} & {$[0.63]$} & {$[0.64]$} & {$[0.61]$} \\
\hline \multirow[t]{2}{*}{ Age (squared) (between-effect) } & $-0.163 * * *$ & $-0.132 * * *$ & $-0.116^{* *}$ & $-0.152 * * *$ & $-0.097^{*}$ \\
\hline & {$[0.04]$} & {$[0.04]$} & {$[0.04]$} & {$[0.04]$} & {$[0.04]$} \\
\hline \multirow{3}{*}{$\begin{array}{l}\text { Non-Australian born (between- } \\
\text { effect) }\end{array}$} & & & & & \\
\hline & $0.397 * * *$ & $0.326 * * *$ & $0.323 * * *$ & $0.403^{* * *}$ & $0.291 * * *$ \\
\hline & {$[0.07]$} & {$[0.06]$} & {$[0.06]$} & {$[0.06]$} & {$[0.06]$} \\
\hline \multirow[t]{2}{*}{ Indigenous (between-effect) } & $-0.640 * * *$ & $-0.460 * * *$ & $-0.516 * * *$ & $-0.540 * * *$ & $-0.369 * * *$ \\
\hline & {$[0.08]$} & {$[0.08]$} & {$[0.08]$} & {$[0.08]$} & {$[0.07]$} \\
\hline \multirow[t]{2}{*}{ Birth weight (between-effect) } & 0.001 & 0 & 0 & 0 & 0 \\
\hline & {$[0.00]$} & {$[0.00]$} & {$[0.00]$} & {$[0.00]$} & {$[0.00]$} \\
\hline \multirow[t]{2}{*}{ Age (within-effect) } & $1.135 * * *$ & $1.051^{* * *}$ & $1.135^{* * *}$ & $1.129 * * *$ & $1.045^{* * *}$ \\
\hline & {$[0.03]$} & {$[0.03]$} & {$[0.03]$} & {$[0.03]$} & {$[0.03]$} \\
\hline \multirow[t]{2}{*}{ Age (squared) (within-effect) } & $-0.043 * * *$ & $-0.042 * * *$ & $-0.043 * * *$ & $-0.043 * * *$ & $-0.042 * * *$ \\
\hline & {$[0.00]$} & {$[0.00]$} & {$[0.00]$} & {$[0.00]$} & {$[0.00]$} \\
\hline \multirow[t]{2}{*}{ Lone parent (between-effect) } & & $-0.185^{* * *}$ & & & $-0.132 * *$ \\
\hline & & {$[0.05]$} & & & {$[0.05]$} \\
\hline \multirow[t]{2}{*}{ Step family (between-effect) } & & $-0.182^{* *}$ & & & $-0.156 *$ \\
\hline & & {$[0.07]$} & & & {$[0.07]$} \\
\hline \multirow[t]{2}{*}{ 2-3 children (between-effect) } & & -0.061 & & & $-0.067\left(^{*}\right)$ \\
\hline & & {$[0.04]$} & & & {$[0.04]$} \\
\hline \multirow[t]{2}{*}{4 or more children (between-effect) } & & $-0.224 * * *$ & & & $-0.149 * *$ \\
\hline & & {$[0.05]$} & & & {$[0.05]$} \\
\hline
\end{tabular}


Table A3. Continued.

\section{Model 1 Model 2 Model 3 Model $4 \quad$ Model 5}

$\begin{array}{ll}\text { Lone parent (within-effect) } & -0.015 \\ \text { Step family (within-effect) } & {[0.03]} \\ & 0.026 \\ \text { Poor household (between-effect) } & {[0.04]} \\ & -0.163^{* *} \\ \text { Maternal education (between-effect) } & {[0.05]} \\ & 0.267^{* * *} \\ \text { Maternal non-employment (between-effect) } & {[0.03]} \\ & 0.027 \\ \text { Maternal age (between-effect) } & {[0.04]} \\ \text { Poor household (within-effect) } & 0.018^{* * *} \\ & {[0.00]} \\ \text { Maternal non-employment (within-effect) } & -0.003 \\ \text { SEIFA index (between-effect) } & {[0.02]} \\ \text { Maternal age (within-effect) } & 0.016 \\ \text { House crowding (between-effect) } & {[0.01]} \\ & 0.069 * * * \\ & {[0.02]} \\ & -0.021 \\ & {[0.02]} \\ & -0.016 \\ & {[0.02]} \\ & \\ \text { House cluttered (between-effect) } & \\ & \\ & \\ & \end{array}$

SEIFA index (between-effect)

Bad neighbourhood (between-effect)

Urban area (between-effect)

SEIFA index (within-effect)

Urban area (within-effect)

Absenteeism (between-effect)

School change (between-effect)

Parent' school involvement (between-effect)

Absenteeism (within-effect)

School change (within-effect)

Parent' school involvement (within-effect)

\begin{tabular}{|c|c|c|}
\hline & & -0.016 \\
\hline & & [0.03] \\
\hline & & 0.023 \\
\hline & & [0.04] \\
\hline & & -0.082 \\
\hline & & {$[0.05]$} \\
\hline & & $0.195 * * *$ \\
\hline & & [0.03] \\
\hline & & 0.043 \\
\hline & & [0.04] \\
\hline & & $0.010 * * *$ \\
\hline & & {$[0.00]$} \\
\hline & & -0.001 \\
\hline & & [0.02] \\
\hline & & 0.015 \\
\hline & & {$[0.01]$} \\
\hline & & $0.071 * * *$ \\
\hline & & {$[0.02]$} \\
\hline & & -0.010 \\
\hline & & {$[0.02]$} \\
\hline & & -0.012 \\
\hline & & [0.02] \\
\hline $0.260 * * *$ & & $0.193 * * *$ \\
\hline$[0.02]$ & & {$[0.02]$} \\
\hline$-0.118^{* *}$ & & $-0.069\left(^{*}\right)$ \\
\hline$[0.04]$ & & [0.04] \\
\hline 0.054 & & $0.066(*)$ \\
\hline$[0.04]$ & & [0.04] \\
\hline-0.019 & & -0.020 \\
\hline [0.02] & & [0.02] \\
\hline $0.064^{*}$ & & $0.066^{*}$ \\
\hline [0.03] & & [0.03] \\
\hline & $-0.480 * * *$ & $-0.330 * *$ \\
\hline & {$[0.11]$} & [0.11] \\
\hline & -0.056 & -0.060 \\
\hline & {$[0.08]$} & [0.08] \\
\hline & $0.702 * * *$ & $0.467 * * *$ \\
\hline & {$[0.06]$} & [0.06] \\
\hline & -0.025 & -0.027 \\
\hline & {$[0.03]$} & [0.03] \\
\hline & 0.010 & 0.008 \\
\hline & {$[0.01]$} & {$[0.01]$} \\
\hline & -0.001 & -0.005 \\
\hline
\end{tabular}


Table A3. Continued.

\begin{tabular}{llllll}
\hline & Model 1 & Model 2 & Model 3 & Model 4 & Model 5 \\
Constant term & $-12.29 * * *$ & $-11.27^{* * *}$ & $-12.19 * * *$ & $-11.98^{* * *}$ & $-11.21^{* * *}$ \\
& {$[2.44]$} & {$[2.36]$} & {$[2.35]$} & {$[2.38]$} & {$[2.28]$} \\
Subjects & & & & & \\
Subject-observations & 3,481 & 3,481 & 3,481 & 3,481 & 3,481 \\
\hline
\end{tabular}

Notes: Hybrid panel regression models. Predictors are measured prior to NAPLAN testing (see methods section). Coefficients can be interpreted as standard deviation change. Standard errors in square brackets under coefficients. $\left({ }^{*}\right)=p<0.1 ; *=p<0.05 ; * *=p<0.01 ; * * *=p<0.001$ 
Table A4. Effects of age-specific relocations on school performance trajectories (full models)

\begin{tabular}{|c|c|c|c|c|c|}
\hline & Model 1 & Model 2 & Model 3 & Model 4 & Model 5 \\
\hline \multicolumn{6}{|c|}{ Relocation age-stage (contemporaneous) } \\
\hline \multirow[t]{2}{*}{ Ages $4 / 5$ to $6 / 7$} & $-0.036 * *$ & $-0.032\left(^{*}\right)$ & $-0.035^{*}$ & $-0.039 *$ & $-0.034^{*}$ \\
\hline & {$[0.02]$} & {$[0.02]$} & {$[0.02]$} & {$[0.02]$} & {$[0.02]$} \\
\hline \multirow[t]{2}{*}{ Ages $6 / 7$ to $8 / 9$} & 0.014 & 0.016 & 0.013 & 0.009 & 0.011 \\
\hline & {$[0.02]$} & [0.02] & {$[0.02]$} & {$[0.02]$} & {$[0.02]$} \\
\hline \multirow[t]{2}{*}{ Ages $8 / 9$ to $10 / 11$} & -0.002 & 0.006 & -0.008 & -0.004 & -0.002 \\
\hline & {$[0.02]$} & {$[0.02]$} & {$[0.02]$} & {$[0.02]$} & {$[0.02]$} \\
\hline \multicolumn{6}{|c|}{ Relocation age-stage (cumulative) } \\
\hline \multirow[t]{2}{*}{ Before age $4 / 5$} & -0.038 & 0.004 & $-0.042\left(^{*}\right)$ & -0.036 & -0.007 \\
\hline & [0.03] & [0.02] & {$[0.02]$} & {$[0.03]$} & {$[0.02]$} \\
\hline \multirow[t]{2}{*}{ Ages $4 / 5$ to $6 / 7$} & -0.048 & 0.006 & -0.034 & $-0.047\left(^{*}\right)$ & 0.009 \\
\hline & {$[0.03]$} & {$[0.03]$} & {$[0.03]$} & [0.03] & {$[0.03]$} \\
\hline \multirow[t]{2}{*}{ Ages $6 / 7$ to $8 / 9$} & -0.014 & -0.004 & -0.004 & -0.013 & 0.004 \\
\hline & {$[0.02]$} & {$[0.02]$} & {$[0.02]$} & {$[0.02]$} & {$[0.02]$} \\
\hline \multicolumn{6}{|c|}{ Other model covariates } \\
\hline \multirow[t]{2}{*}{ Female } & $0.201 * * *$ & $0.208 * * *$ & $0.203^{* * *}$ & $0.201 * * *$ & $0.209 * * *$ \\
\hline & {$[0.02]$} & {$[0.02]$} & {$[0.02]$} & {$[0.02]$} & {$[0.02]$} \\
\hline \multirow[t]{2}{*}{ Age (in months) } & $1.117^{* * *}$ & $1.092 * * *$ & $1.114^{* * *}$ & $1.113^{* * *}$ & $1.092 * * *$ \\
\hline & {$[0.03]$} & {$[0.03]$} & {$[0.03]$} & {$[0.03]$} & {$[0.03]$} \\
\hline \multirow[t]{2}{*}{ Age (squared) } & $-0.042 * * *$ & $-0.042 * * *$ & $-0.042 * * *$ & $-0.042 * * *$ & $-0.042^{* * *}$ \\
\hline & {$[0.00]$} & {$[0.00]$} & {$[0.00]$} & {$[0.00]$} & {$[0.00]$} \\
\hline \multirow[t]{2}{*}{ Non-Australian born } & $0.396 * * *$ & $0.336 * * *$ & $0.354 * * *$ & $0.394 * * *$ & $0.309 * * *$ \\
\hline & {$[0.07]$} & {$[0.06]$} & {$[0.06]$} & [0.07] & {$[0.06]$} \\
\hline \multirow[t]{2}{*}{ Indigenous } & $-0.644 * * *$ & $-0.494 * * *$ & $-0.562 * * *$ & $-0.636 * * *$ & $-0.448 * * *$ \\
\hline & {$[0.08]$} & {$[0.08]$} & {$[0.08]$} & {$[0.08]$} & {$[0.08]$} \\
\hline \multirow[t]{2}{*}{ Birth weight } & 0.001 & 0 & 0 & 0.001 & 0 \\
\hline & {$[0.00]$} & {$[0.00]$} & {$[0.00]$} & {$[0.00]$} & {$[0.00]$} \\
\hline \multirow[t]{2}{*}{ Lone parent } & & $-0.085 * * *$ & & & $-0.082 * * *$ \\
\hline & & {$[0.02]$} & & & {$[0.02]$} \\
\hline \multirow[t]{2}{*}{ Step family } & & $-0.076 *$ & & & $-0.070 *$ \\
\hline & & {$[0.03]$} & & & [0.03] \\
\hline \multirow[t]{2}{*}{ 2-3 children } & & -0.027 & & & -0.035 \\
\hline & & {$[0.04]$} & & & {$[0.04]$} \\
\hline \multirow[t]{2}{*}{4 or more children } & & $-0.200 * * *$ & & & $-0.178 * * *$ \\
\hline & & {$[0.05]$} & & & {$[0.05]$} \\
\hline \multirow[t]{2}{*}{ Poor household } & & -0.023 & & & -0.020 \\
\hline & & {$[0.01]$} & & & {$[0.01]$} \\
\hline \multirow[t]{2}{*}{ Maternal age } & & $0.289 * * *$ & & & $0.259 * * *$ \\
\hline & & {$[0.03]$} & & & {$[0.03]$} \\
\hline \multirow[t]{2}{*}{$\begin{array}{l}\text { Maternal non- } \\
\text { employment }\end{array}$} & & 0.017 & & & 0.018 \\
\hline & & {$[0.01]$} & & & {$[0.01]$} \\
\hline
\end{tabular}


Table A4, continued.

\begin{tabular}{|c|c|c|c|c|c|}
\hline & Model 1 & Model 2 & Model 3 & Model 4 & Model 5 \\
\hline \multirow[t]{2}{*}{ Maternal age } & & $0.021 * * *$ & & & $0.017 * * *$ \\
\hline & & {$[0.00]$} & & & {$[0.00]$} \\
\hline \multirow[t]{2}{*}{ House crowding } & & -0.023 & & & -0.017 \\
\hline & & {$[0.02]$} & & & {$[0.02]$} \\
\hline \multirow[t]{2}{*}{ House cluttered } & & -0.014 & & & -0.015 \\
\hline & & {$[0.02]$} & & & {$[0.02]$} \\
\hline \multirow[t]{2}{*}{ SEIFA index } & & & $0.134 * * *$ & & $0.103 * * *$ \\
\hline & & & {$[0.01]$} & & {$[0.01]$} \\
\hline \multirow[t]{2}{*}{ Bad neighbourhood } & & & $-0.145^{* * *}$ & & $-0.109 * *$ \\
\hline & & & {$[0.04]$} & & {$[0.04]$} \\
\hline \multirow[t]{2}{*}{ Urban area } & & & $0.078 * * *$ & & $0.078 * * *$ \\
\hline & & & {$[0.02]$} & & {$[0.02]$} \\
\hline \multirow[t]{2}{*}{ Absenteeism } & & & & $-0.049 *$ & $-0.042\left(^{*}\right)$ \\
\hline & & & & {$[0.02]$} & {$[0.02]$} \\
\hline \multirow[t]{2}{*}{ School change } & & & & 0.014 & 0.013 \\
\hline & & & & {$[0.01]$} & {$[0.01]$} \\
\hline \multirow{2}{*}{\multicolumn{2}{|c|}{ Parent' school involvement }} & & & $0.030^{*}$ & 0.018 \\
\hline & & & & {$[0.01]$} & {$[0.01]$} \\
\hline \multirow[t]{2}{*}{ Intercept } & $-6.567 * * *$ & $-7.383^{* * *}$ & $-7.965 * * *$ & $-6.575^{* * *}$ & $-8.331 * * *$ \\
\hline & {$[0.15]$} & {$[0.18]$} & {$[0.20]$} & {$[0.15]$} & {$[0.21]$} \\
\hline \multicolumn{6}{|l|}{ Random part (var) } \\
\hline Age & 0.001 & 0.001 & 0.001 & 0.001 & 0.001 \\
\hline Intercept & $0.688 * * *$ & $0.664 * * *$ & $0.668 * * *$ & $0.687^{* * *}$ & $0.651 * * *$ \\
\hline Subjects & 3,481 & 3,481 & 3,481 & 3,481 & 3,481 \\
\hline Subject-observations & 8,609 & 8,609 & 8,609 & 8,609 & 8,609 \\
\hline
\end{tabular}

Notes: Random-coefficients regression models. Predictors are measured prior to NAPLAN testing (see methods section). Coefficients can be interpreted as standard deviation change. Standard errors in square brackets under coefficients. $\left({ }^{*}\right)=p<0.1 *^{*}=p<0.05 ; *^{*}=p<0.01 ; *^{* *}=p<0.001$ 